\title{
APRESENTAÇÃO DE PACIENTES: (RE)DESCOBRINDO A DIMENSÃO CLÍNICA
}

Cristiana Miranda Ramos Ferreira

Psicóloga e psicanalista; mestre em Psicologia, UFMG, e especialista em Saúde Mental - Clínica.
RESUMO: Nos últimos anos, a prática da apresentação de pacientes vem crescendo no campo psicanalítico, e isto se deve, sem dúvida, aos incontestáveis efeitos clínicos por ela produzidos. Para se fazer uma análise crítica e avançar nas elaborações e sistematizações acerca da apresentação, é preciso conhecer as bases conceituais sobre as quais o processo se deu. Procura-se, aqui, esboçar um mapeamento histórico, procurando identificar as circunstâncias de seu surgimento, transformações pelas quais passou, até seu uso no momento atual.

Palavras-chave: Apresentação de pacientes, psicanálise, clínica.

ABSTRACT: Patient Presentation: (re)discovering the clinical dimension. On the last years, the practice of patient presentation comes growing in the psychoanalytic field, and this is, without a doubt, because of the incontestable clinical effects that it produces. To become a critical analysis and to advance in the elaborations concerning the presentation, it is necessary to know the conceptual bases on which the process occurred. This work has as objective to sketch a historical mapping, seeking for identifying the circumstances of its sprouting, transformations through which it passed until its use at the current moment.

Keywords: Presentation of patients, psychoanalysis, clinic.

A o se posicionar no campo da Saúde Mental, o analista cidência do discurso analítico implica a introdução de um saber que favorece a singularidade no interior da instituição tradicionalmente médica. Uma pergunta que se coloca é: como abrir espaço ao sujeito da palavra no interior de uma instituição que opera com uma lógica universalizante e silenciadora? Ainda que não seja uma tarefa fácil, não é sem precedentes. Podemos buscar inspiração no trabalho de Lacan que, por cerca 
de 30 anos realizou apresentações de pacientes em hospitais psiquiátricos. Ao associar a psicanálise a essa prática, tradicionalmente médica, Lacan não apenas proporcionou um diálogo acerca da interseção entre psiquiatria e psicanálise, mas possibilitou, sobretudo, que a fala do paciente ressoasse no universo institucional. Como nos indica François Leguil, “(...) a apresentação de Lacan é hoje a pedra angular de nossa reflexão sobre a presença do analista no hospital” (LEGUIL, 1998, p.99).

E não apenas as apresentações de Lacan. De fato, demos continuidade à prática de Lacan. Pelo menos no Campo Freudiano, as apresentações têm se tornado freqüentes, não apenas enquanto prática realizada em instituições de tratamento, mas também nos encontros e conversações, nas quais seus efeitos clínicos e institucionais têm sido tema de discussão. Experiências que, como nos disse J. A. Miller no Conciliabule d'Anger (1998), por estarem acontecendo em escala maior, já nos permitem algumas elaborações.

É por isso que, mesmo sabendo que debater sobre a prática das apresentações de pacientes é entrar num terreno polêmico e controverso, nós, psicanalistas, não podemos nos furtar de avançar nessa discussão. Afinal, se, vez por outra, o repúdio a este exercício volta à cena, o que nossa prática nos ensina é que, realizada seguindo os pressupostos psicanalíticos, a apresentação pode ser um importante dispositivo clínico, que produz efeitos sobre o paciente, sobre a equipe e sobre a instituição.

A falta de consenso em torno da prática da apresentação de pacientes é, podemos dizer, histórica. Ao longo dos anos, ela encontrou tanto praticantes fiéis, como opositores implacáveis. Foi condenada por uns, defendida por outros, ou simplesmente utilizada sem maiores questionamentos por outros tantos.

Assim, se quisermos nos posicionar nessa conversa, é preciso reconhecer, de início, que, se há críticas, estas não são de todo infundadas. É verdade que a apresentação de pacientes é um dispositivo de aplicação prática de uma teoria, operando, assim, em acordo com os princípios éticos e ideológicos daquele que dela se utiliza. Ou seja, esta não é uma prática homogênea, mas ao contrário, tem tantos senhores quanto diversidade de abordagens psiquiátricas.

Assim, como nos indica Lantéri-Laura, reconhecer o campo histórico é fundamental:

“Somente esse tipo de esclarecimento [histórico] pode nos ajudar a relativizar o próprio presente da psiquiatria, pois só podemos adotar uma atitude de interesse crítico frente à psiquiatria de 1980 (no nosso caso, a apresentação atual), sob a condição de ver nela o desembocar e a complicação progressiva de um conjunto de questões que começaram a ser levantadas pelo menos no final do século XVIII. Logo, esclarecer o presente pelo conhecimento de seu passado e, pelo mesmo movimento, relativizá-lo: o es- 
tudo histórico aparece, assim, como o meio para um conhecimento mais exato da psiquiatria, conhecimento que possui um valor prático incontestável e que nunca se limita a um adorno erudito.” (LANTÉRI-LAURA, 1989, p.14, grifos nossos)

\section{SOBRE O NASCIMENTO DA APRESENTAÇÃO DE PACIENTES}

A apresentação de pacientes é uma prática originalmente psiquiátrica que consiste no exame do paciente, realizado pelo médico diante de um público composto, em geral, pelo corpo clínico e por alunos.

De acordo com Michel Foucault (2005), teríamos como primeiro indício do uso da apresentação de pacientes, uma proposta de um curso de clínica das enfermidades mentais oferecido por Esquirol, em Salpêtrière, já em 1817.

Uma primeira observação que podemos extrair dessa informação de Foucault é o quão precoce foi o surgimento da prática da apresentação em relação ao surgimento da própria psiquiatria. Se consideramos que o nascimento da psiquiatria se dá no ano de 1793, data em que Pinel assumiu suas funções em Bicêtre, como propôs Foucault em sua célebre História da loucura (1972), temos que esta, e a apresentação de pacientes, são praticamente contemporâneas. Outra informação importante é que, em se tratando de um 'curso de clínica', temos, nesta primeira referência à sua utilização, que a apresentação de pacientes surgiu enquanto dispositivo destinado ao ensino da psiquiatria. Precisamos, pois, reconhecer na apresentação uma vocação didática, sem, no entanto, reduzi-la a isto. Pelo contrário, nesse momento de seu nascimento, a apresentação de pacientes constitui, para além do ensino, um importante instrumento clínico.

Um instrumento clínico tão adequado a essa psiquiatria nascente que, segundo Foucault (2005), no período de 1830-1835, a prática de apresentação já havia alcançado tal repercussão que, na França, era exercida por todo chefe de serviço, mesmo por aqueles que não estavam envolvidos com o ensino.

No período anterior à 'revolução' de Pinel, a concepção da loucura era marcada pela crença na incurabilidade. Os médicos de então tinham absoluto desinteresse seja pelo bem-estar dos doentes, seja pela observação de seus sintomas, ou pelo seu tratamento.

Mitificado como o homem que libertou os loucos de suas algemas, o ato de Pinel não era apenas humanitário, mas estava guiado por interesses científicos. Ele sustentava ser impossível determinar se os sintomas mentais resultavam de doença mental ou dos efeitos das correntes e das distorções impostas pelo desconforto e violência, até cruel, das administrações dos velhos hospícios (PESSOTTI, 1996). Ele entendia que o homem alienado deveria ser bem tratado, para poder assim ser observado, analisado empiricamente. Pautados pela necessidade de diagnóstico e tratamento corretos da loucura, Pinel introduziu assim o chamado 
'método clínico', que implicava na observação prolongada, rigorosa e sistemática dos pacientes, transformando-os de loucos em verdadeiros doentes mentais.

Pinel fez uma redefinição profunda das funções do manicômio. Com Pinel, o manicômio passou de lugar de depósito, a ser parte essencial do tratamento, um 'instrumento de cura'. Segundo Isaias Pessoti:

“Nesse projeto [de Pinel], o manicômio deveria ter duas funções básicas e peculiares: servir como ambiente privilegiado para a observação sistemática do comportamento dos pacientes, a fim de refinar os diagnósticos e, de outro lado, assegurar aos pacientes experiências reais que corrigissem pedagogicamente os vícios de sua razão desviada.” (PESSOTTI, 1996, p.167)

Ou seja, nesta época acreditava-se que a cura derivaria do próprio funcionamento do asilo: do isolamento, que permitia que a loucura se manifestasse em sua forma verdadeira; e do rigor das normas e regras sustentadas em medidas punitivo-terapêuticas, que visavam controlar e adequar o comportamento do louco, sustentados na presença física do médico. A estratégia era vulnerar, furar a onipotência da loucura submetendo-a a uma vontade ainda mais vigorosa e dotada de um poder superior: a realidade do médico. ${ }^{1}$

O que podemos ver é que a apresentação de pacientes atendia a essas duas proposições de Pinel para o manicômio. Por um lado, a apresentação servia como um dispositivo muito apropriado para a observação e para o estudo minucioso do enfermo, visto que favorecia a apreensão dos fenômenos a partir de sua descrição, detalhada pelo próprio paciente. Por outro lado, as condições em que a observação se dava eram muito favoráveis para estabelecer a relação médicopaciente, essencial, na concepção de Pinel, para esse tipo de tratamento.

A apresentação era feita na forma de um interrogatório que colocava o paciente numa posição de submissão ao saber do médico. Isto porque, diferente do que poderíamos imaginar, a intenção do médico não era obter informações sobre o paciente (ainda que isso ocorresse), pois de fato ele ia para o interrogatório munido de informações detalhadas sobre o paciente - tanto sobre sua história de vida, quanto de sua doença, como de seu comportamento no asilo. A intenção do interrogatório era levar o paciente a reconhecer sua doença, pois se acreditava que o primeiro passo para o tratamento era o reconhecimento desta - somente a partir da confissão da doença, o enfermo poderia desfazer-se dela.

\footnotetext{
${ }^{1}$ Para entendermos melhor, a idéia do poder/presença do médico como forma de tratamento, tomemos um exemplo de Georget (1795-1828), apresentado por Foucault. Georget dava como conselho aos médicos que não se deveria negar a um alienado a condição que este pretendia ter. Se o paciente dizia ser rei, pois bem, era preciso mostrar-lhe que, mesmo sendo rei, ele carecia de poder, estando, portanto, submetido ao médico e que, este sim, podia tudo sobre seu paciente (FOUCAULT, 2005, p.175).
} 
A estratégia fundamental para levar o paciente à confissão era a confrontação do que este dizia com aquilo que o médico sabia sobre ele. O objetivo é que o paciente abrisse mão de sua realidade delirante, de sua realidade particular, e chegasse não apenas a consentir com a realidade socialmente compartilhada, reconhecida, mas também com a verdade de sua doença, de sua loucura. E ainda mais, era preciso evidenciar a crise, atualizá-la concretamente: "Sim, escuto vozes!”; “Sim, tenho alucinações!"; "Sim, creio ser Napoleão! E isso é minha doença.”2

Assim, o interrogatório foi uma das principais estratégias de intervenção para a psiquiatria do século XX, que entendia que tratar a loucura era adequar o louco à realidade. A apresentação de pacientes é sim a forma como ficou conhecida a realização do interrogatório do paciente quando realizada diante de um público. Assim, o interrogatório, e conseqüentemente a apresentação, se consolidaram como importantes maneiras de extrair a verdade do paciente, de levá-lo a dizer a verdade.

Apesar de não haver relatos diretos sobre os efeitos terapêuticos do interrogatório ou, mais especificamente, da apresentação, esta se tornou, como já dissemos, um dos procedimentos mais importantes e mais constantes dentro da prática psiquiátrica.

Tanto que, mesmo no período posterior, quando em função da ênfase maior na visão organicista o tratamento moral começou a cair no descrédito e o manicômio deixou de ser, ele mesmo, um instrumento de cura, a importância da apresentação de pacientes se manteve. Podemos supor que isso se deu porque, mesmo que o jogo de forças e poder do médico sobre o paciente tivesse perdido um pouco seu sentido terapêutico, por outro lado, a apresentação continuava servindo como excelente dispositivo de investigação diagnóstica e de constituição do saber psiquiátrico.

Psiquiatras como Griesinger (1817-1868), que ficou conhecido como 'o primeiro dos organicistas' e influenciou toda a geração posterior, mesmo focando o interesse de suas investigações no locus orgânico da doença, não descartou a importância de conhecimento dos pormenores da personalidade do paciente como forma de conhecer a doença.

Jean Pierre Falret, psiquiatra francês, que recebeu influências de Griesinger, por exemplo, no seu livro De L'enseignement clinique des maladies mental (1850), colocava o interrogatório público no primeiro plano do exame clínico. Segundo ele, era possível perceber nestas situações o esforço do paciente em responder às questões, talvez como forma de compensar o esforço, que percebiam, da dedicação do médico:

\footnotetext{
${ }^{2}$ Referindo-se aqui ao sr. Dupré, cuja 'cura' foi relatada por F. Leuret em Du Traitement moral de la folie - 1840, e trabalhada por Foucault. Conf.: El poder psiquiátrico (2005), Clase del 9 de enero de 1974 .
} 
“com freqüência, o relato de sua enfermidade, feito em todas as suas vicissitudes, impressiona intensamente os alienados, que dão testemunho de sua verdade com uma satisfação visível e se comprazem em entrar em maiores detalhes para completar seu relato, assombrados e envaidecidos, de certo modo, de que se tenham ocupado deles com suficiente interesse para poder conhecer toda sua história." (FALRET apud FOUCAULT, 2005, p.221) $)^{3}$

Dessa forma, longe de uma dimensão puramente didática, a apresentação se consolidou com uma dimensão marcadamente clínica: de investigação de descrição de diversas síndromes e entidades nosológicas. Podemos mesmo dizer que, dentre as intervenções no asilo, foi justo o interrogatório que mais aproximou a atuação médica de um trabalho realmente clínico. Afinal, ele colocava o médico no exame direto do paciente. Assim, temos, na apresentação, o médico em duplo registro: de examinador do paciente e educador, mestre dos alunos - ao mesmo tempo numa função de cura e de ensino.

Contudo, não obstante seu importante caráter clínico, um aspecto curioso é que, na maior parte dos textos em que encontramos alguma referência às apresentações de paciente realizadas pelos representantes da psiquiatria clássica, tanto francesa, quanto alemã, estas são caracterizadas como um dispositivo eminentemente didático, caracterizado pela exibição do saber do mestre, sustentado na exposição pública do paciente. A pergunta que se coloca é: por que nos relatos históricos essa dimensão clínica ficou relegada a um segundo plano? Ou melhor, seria dizer: Por que ela passou a ser ignorada, esquecida?

\section{SOBRE O DECLÍNIO DAS APRESENTAÇÕES DE PACIENTE}

Encontramos algumas indicações que nos levam a pensar que essa caracterização da apresentação como dispositivo didático em essência é um retrato do uso desse dispositivo num período muito particular, mais precisamente, a partir da segunda metade do século XX.

Segundo Francisco Paes Barreto, em meados do século XX a psiquiatria clássica, por ser detentora de um saber já constituído, atravessava uma fase de estagnação. Esta já não apresentava mais progresso dos conhecimentos semiológicos ou nosológicos, uma vez que seu método descritivo já havia chegado ao limite de suas possibilidades (BARRETO, 1988).

Vemos, assim, que a psiquiatria perde o equilíbrio em que se encontrava - no cruzamento entre aquilo que investigava, aquilo que encontrava e o que conseguia transmitir. Numa posição de observação pura e simples, se acomodara em “seu saber” então constituído. A apresentação, que funcionava como ponto de

\footnotetext{
${ }^{3}$ Tradução livre do espanhol.
} 
aplicação e produção de saber, perdeu seu lugar dinâmico de invenção, ficando abandonada ao automatismo acadêmico, restringindo-se à função de "ilustração viva" dos quadros conhecidos, que é justamente a imagem que chegou até nós (LEGUIL, 1998).

Associado a essa crise interna da psiquiatria clássica, a ênfase na concepção organicista que ganhou força na segunda metade do século XIX, transformara o tratamento manicomial em um conjunto de intervenções bastante violentas, calcadas na idéia de que somente por meio de intenso sofrimento físico, se poderia atuar sobre o cérebro doente terapêutico. Essa situação tornara-se ainda mais insustentável no pós-guerra, o que favoreceu o surgimento de movimentos humanitários que passaram a questionar as instituições, os manicômios e suas práticas de tratamento.

Dentre esses movimentos, merece destaque a antipsiquiatria, cujos maiores expoentes foram os psiquiatras ingleses Laing e Cooper. Este movimento, ocorrido nos anos 1960 do século passado, fez severas críticas à psiquiatria clássica. Buscava destruir o valor do saber/poder médico, colocando em questão sua função médica de produção da verdade da doença no espaço hospitalar.

Com relação à apresentação de pacientes, os representantes da antipsiquiatria, não apenas a condenavam como um instrumento de abuso do poder médico, como a escolheram como paradigma, como referência ilustrativa, para demonstrar o ápice desse poder. Usaram como bandeira a figura de Charcot, que havia ficado conhecido entre outros motivos, por suas célebres apresentações.

Charcot foi de um período bem anterior à antipsiquiatria. Seu momento mais profícuo e suas apresentações mais famosas se deram por volta de 1885/1887. Entretanto, estas apresentações ficaram na história por serem verdadeiros espetáculos - a título de verificação científica e ensino, ele submetia os pacientes histéricos à hipnose, utilizando-se da sugestionabilidade desses para fabricar os sintomas que desejava demonstrar. Esse procedimento que, muitas vezes, chegou mesmo a se confundir com espetáculos circenses, foi tomado como marco de abuso e objetificação. A forma como a antipsiquiatria se apropriou e falou da apresentação, foi outro fator que influenciou a idéia que nos chegou do que teria sido esta prática enquanto um dispositivo unicamente didático. Idéia que ainda habita o imaginário daqueles que a utilizam e, sobretudo, daqueles que condenam a prática de apresentação de pacientes.

Podemos destacar ainda uma terceira situação que influenciou de modo decisivo na imagem da apresentação de pacientes enquanto dispositivo essencialmente didático. Por volta dos anos 1950, o desenvolvimento alcançado pela psicofarmacologia favoreceu o desenvolvimento de uma 'clínica da medicação'. O surgimento do DSM, em 1952, como um modelo de procedimento operacional, que tinha por base uma 'resposta padrão', a administração de determinada 
substância, visando preencher a ausência de signos patognomônico e exames laboratoriais em psiquiatria. Segundo Laurent, "temos aí, nesse modelo, uma redução do saber que se quer obter, pois poucos pontos passaram a servir de parâmetro para atender à sua necessidade, hoje reduzida a medicar o sintoma" (CLASTRES et al., 1991).

Neste caso, porque não há mais interesse nos detalhes fornecidos pela fala do paciente, o uso da apresentação permaneceu, mas ficou reduzida a um dispositivo universitário, demonstrativo. Afinal, sendo a apresentação uma prática intrinsecamente articulada ao saber psiquiátrico que a condiciona, não poderia operar de outra forma. Na medida que esta psiquiatria se serviu da apresentação, esta só poderia se dar neste mesmo formato reduzido, empobrecido ${ }^{4}$. "Sua única vocação é ilustrar aquilo que se professa para animar o saber, mas a apresentação já não faz prova de verdade de uma confrontação como fazia” (LEGUIL, 1998, p.199).

Assim, a prática da apresentação tão importante, tão utilizada pela psiquiatria clássica, perde seu lugar de destaque, enquanto instrumento clínico, até sua (re)apropriação por Lacan.

\section{AS APRESENTAÇÕES DE LACAN}

Assim, em meados do século XX, apesar de já não ter mais o mesmo lugar de destaque, a apresentação era uma prática comum nos hospitais. Entretanto, em lugar do aspecto clínico, de intervenção e produção de saber médico, que a caracterizaram em sua origem, ela adquirira um caráter marcadamente didático: os pacientes eram expostos aos estudantes de psiquiatria como ilustração de pontos específicos da teoria, de quadros clínicos e de fenômenos psicopatológicos. A apresentação de pacientes era, portanto, um espaço de demonstração, tanto dos fenômenos apresentados pelo paciente, quanto do saber do mestre, do professor que fazia a entrevista. Pode-se dizer que, marcada pelo empobrecimento deste caráter puramente didático, e pelos ataques de seus opositores, a prática da apresentação estava ameaçada de desaparecimento, de cair no esquecimento.

Curiosamente, em lugar de aderir às interrogações colocadas à apresentação e mesmo à psiquiatria clássica, Lacan encontrou interesse nessa psiquiatria agonizante e sustentou sua importância. De fato, a crítica de Lacan à psiquiatria de sua época era severa. Mais do que evocar esse saber clássico, Lacan interrogava o abandono de seu caráter investigativo, e colocava em questão o alcance da psiquiatria atual.

\footnotetext{
${ }^{4}$ Entendendo aqui, 'empobrecimento', enquanto abordagem focada no sintoma e não mais nos mecanismos de sua formação expressa na fala do paciente.
} 
Seu interesse pela psiquiatria clássica englobava também a prática da apresentação de pacientes, a qual Lacan não apenas retomou, mas, podemos mesmo dizer, renovou, ou ainda mais - Lacan a subverteu.

Como nos indica François Leguil, "se Jacques Lacan, indo contra o senso comum, preservou essa prática, não seria pelo fato de considerar que se devia ainda procurar nela e nela encontrar uma relação específica e insubstituível com a verdade que está em causa na clínica?” (LEGUIL, 1989, p.97).

Clínica que conheceu com Clérambault (1872-1934), seu mestre em psiquiatria, considerado por muitos como o último dos grandes psiquiatras clássicos; e que sustentou na psicanálise, na medida que, como o próprio Lacan irá dizer: “ser psicanalista é hoje ser clínico, já que, hoje, ser clínico é não ser mais verdadeiramente psiquiatra"(Lacan apud LEGUIL, 1989, p.97).

Lacan, por volta dos anos 1930, já se interessava pelo relato do paciente. Assim, nas suas apresentações, como ele mesmo diria mais tarde, a palavra era do paciente.

“Em suma, e para lhe prestar homenagem, foi em torno dessa paciente, Aimée, que fui aspirado para a psicanálise. Não foi só ela, é claro, alguns outros antes e muitos depois para quem dei a palavra, eis em que consistem minhas apresentações de pacientes." (LACAN, 1972, CR Rom $)^{5}$ (Grifo nosso)

E na medida que se formou psicanalista, é do lugar de analista que ele fará suas apresentações. Assim, Lacan manteve a forma de entrevista pública, mas em lugar da função didática, de demonstração teórica própria das apresentações de sua época, ao associar a psicanálise à apresentação, Lacan lhe imprimiu um caráter fundamentalmente clínico. Contudo, a clínica que Lacan operava, longe da vertente do interrogatório e da confrontação do paciente e da produção da crise, sustentava-se na crença na "virtude da palavra" para mudar a clínica de um caso.

De fato, ao aplicar a escuta psicanalítica a essa prática originalmente psiquiátrica, Lacan a renovou, pois introduziu no dispositivo da apresentação a subversão freudiana. Como sabemos, Freud subverteu a perspectiva médica justamente ao deslocar o lugar do saber do médico para o paciente. Assim, instituiu uma clínica que supera essa perspectiva médica, estabelecendo um verdadeiro corte discursivo — o sujeito, até então alienado no saber médico, toma a palavra — é ele quem tem algo a dizer. Não se trata de classificá-lo ou de dar-lhe respostas, mas, antes, de dar-lhe condições para que produza, ele mesmo, um saber sobre seu sofrimento.

\footnotetext{
${ }^{5}$ Tradução livre do espanhol.
} 
O que Lacan fez, enquanto psicanalista, foi acolher o paciente, durante a entrevista, deste mesmo lugar proposto por Freud. E se ele acolhe o sujeito, ele o faz por supor que haja ali algo a ser escutado. Não é por ter um saber a mais - um saber sobre o paciente e sobre sua doença —, mas ao contrário, é por reconhecer que algo lhe escapa e que sobre isso só o sujeito pode dizer, e ele, Lacan, escuta.

Lacan fez então uma mudança radical em relação às demais apresentações realizadas por seus contemporâneos: na apresentação de Lacan é o paciente quem fala, é ele quem ensina. O interesse de Lacan se desloca do saber preexistente ao dizer do paciente, para os aspectos do caso que escapam a um saber preestabelecido. $\mathrm{O}$ sujeito é interrogado para nos instruir sobre o seu caso, sobre a interpretação que faz de sua própria história - por isso dizemos que o saber está do lado do paciente. Esse é o sentido que podemos dar à frase de J.A. Miller: "O ensino dos doentes, na apresentação de Lacan, é assim que é preciso dizer...” (1996, p.146).

Ainda que as apresentações fossem muito ricas, do ponto de vista psicopatológico — de percepção dos sintomas, e de investigação diagnóstica — , seu interesse não se limitava a isto. Com Lacan, não havia mais produção de crise, nem exploração dos sintomas. Ele, longe de uma demonstração de fenômenos, procurava localizar a posição subjetiva do paciente, ou seja, procurava, ia atrás dos indícios da posição de gozo do sujeito, de sua posição na relação com o Outro, com a linguagem.

Como efeito, segundo Éric Laurent (1989), o que se podia ver era a surpresa dos psiquiatras diante do trabalho de Lacan, pois o que presenciavam ali não era em nada parecido com o que tinham conhecido em sua própria formação. Em lugar de uma entrevista para demonstração dos sintomas do doente, podiam testemunhar o encontro de um psicanalista com um sujeito. Como nos diz Claude Léger: "duas pessoas conversando normalmente diante de um auditório atento a este colóquio singular” (LÉGER, 1998).

A forma como Lacan realizava suas apresentações colocava a trabalho, não apenas o paciente, mas também seus alunos. Em 1974, um grupo de psicanalistas começou a se reunir após algumas das apresentações para:

"discutir, tentar compreender como o dr. Lacan procedia, o que ele mesmo buscava, sobre o que tinha posto ênfase, o que tentava nos ensinar quando aí se punha de uma certa maneira, quando comentava de uma determinada forma. Tentávamos compreender a maneira como interrogava, e, efetivamente, o modelo; o que fazia o dr. Lacan." (LAURENT,1989, p.151)

E foi esse tipo de discussão que Lacan possibilitava que, como dissemos, acabou por acentuar o caráter clínico desse trabalho — em lugar da restrição a 
seu objetivo de ensino, de diagnóstico, nessas reuniões discutia-se a dimensão mesma do tratamento, mais precisamente, de sua direção. Este trabalho passou a ter, então, como objetivo, orientar o que, sob o ponto de vista psicanalítico, podia ser feito a propósito do tratamento em questão.

Não apenas a forma de entrevista de Lacan, mas também esse exercício de se reunir para trabalhar um caso clínico após a entrevista, continua presente na prática dos psicanalistas lacanianos até os dias atuais.

\section{APRESENTAÇÕES NA ATUALIDADE: DO VALOR DIDÁTICO AO EFEITO CLÍNICO}

Apesar de todas as controvérsias, polêmicas e modificações pelas quais passou a prática da apresentação de pacientes ao longo de sua história, esta continua presente nas instituições de tratamento psiquiátrico.

Com relação às apresentações realizadas pelos psicanalistas de formação lacaniana, podemos dizer que estas têm estado cada vez mais presentes em nossa prática.

De fato, Lacan introduziu modificações de tal forma fundamentais em sua forma de fazer a apresentação, que esta teve alteradas não apenas as articulações entre os elementos (paciente, público e entrevistador), mas também o seu objetivo e alcance, sendo hoje, considerada valioso instrumento de intervenção clínica e de transmissão da psicanálise.

Podemos dizer que essa forma de realizar a apresentação de pacientes a partir da psicanálise é tão diferente da prática psiquiátrica que podemos mesmo, a título de facilitar a contraposição, dividir em dois os tipos de apresentação de enfermos: por um lado, a apresentação de pacientes conforme a proposição de Lacan, marcada pela escuta analítica, que chamaremos de 'apresentação clínica'. E, por outro, as demais apresentações, que chamaremos de 'tradicionais'.

A diferença fundamental é quanto ao lugar de saber. Na apresentação tradicional, o entrevistador opera segundo o discurso médico, ou seja, a partir do saber do mestre, preexistente ao dizer do paciente. Nesta situação, a fala do enfermo é transformada em signos, em sinais médicos, sendo reduzida àquilo que pode ser inscrito em suas classificações, inscrito em seu campo de saber.

Já na apresentação clínica, como realizada a partir da proposta de Lacan, temos uma mudança radical quanto ao lugar do saber. Como o interesse está em trabalhar a partir da singularidade, não é possível operar com um saber a priori, uma vez que não há como inferir que interpretação o sujeito dá à sua história. Assim, o paciente ocupa uma posição de saber, sendo o sujeito convidado a nos instruir sobre o seu caso, sobre seu sofrimento e sobre as saídas que tem encontrado.

Nesta situação, o analista não tem um saber constituído para demonstrar, como na apresentação tradicional. Pelo contrário, na apresentação clínica, o 
apresentador se coloca num lugar de não saber, e tenta, a partir desse lugar, interrogar o sujeito para aprender algo do que lhe ocorre, ficando numa posição de ser ensinado pelo paciente, pois é do lado deste que se produz o saber que ensina. Com esta posição de esvaziamento do saber prévio, Lacan introduziu, aí, na apresentação, a dimensão de tyché, de surpresa, que corresponde ao encontro do paciente com aquele que o interroga (QUINET, 1997) e que pode, justamente possibilitar que algo novo apareça: o momento do desencadeamento, um significante novo, um neologismo, as premissas de uma transferência...

Este 'novo' pode possibilitar importantes efeitos no tratamento: o esclarecimento diagnóstico, indicações de premissas de uma transferência, perspectivas de estabilização, são exemplos de aspectos que podem ser esclarecidos, ou redefinidos, a partir de elementos surgidos durante uma entrevista.

Como efeito, esses elementos podem ser recolhidos pela equipe e aplicados ao tratamento. Pois, efetivamente, a apresentação possibilita fazer uma apreciação mais cuidadosa do caso. De fato, a apresentação é um excelente dispositivo clínico, que por permitir que o caso seja interrogado a partir da fala do próprio paciente, tomando por base suas particularidades e o que de singular o sujeito revela, a apresentação, de hábito, favorece o que chamamos de 'construção do caso clínico', auxiliando no esclarecimento do diagnóstico, no estabelecimento de intervenções mais adequadas, na reavaliação do prognóstico. Enfim, permite redefinir a direção do tratamento e a implicar a equipe a partir de um cálculo de ações de cada um de seus membros, dentro de uma estratégia coletiva de intervenção — produzindo efeitos que em geral podem ser constatados a posteriori.

Nossa experiência com apresentação ${ }^{6}$ tem demonstrado, inclusive, que a intervenção sobre o tratamento costuma obter resultados tão significativos nos chamados 'casos difíceis', que esse dispositivo desperta o interesse da comunidade clínica, até mesmo dos profissionais de formações outras que não a psicanalítica. Diante de impasses da clínica, ao se encontrarem com seus recursos esgotados, muitos deles acabam por demandar esses espaços, buscando outras soluções, que não as tradicionalmente utilizadas. Assim, o que vemos é que esse dispositivo possibilita que a lógica psicanalítica circule, servindo de orientador último para o trabalho de uma equipe, mesmo que heterogênea quanto à formação de seus profissionais.

\footnotetext{
${ }^{6}$ Tomamos como referência, um trabalho de seis anos de apresentações de paciente no Instituto Raul Soares (IRS), hospital psiquiátrico da rede Fhemig, no qual aconteciam, regularmente, dois espaços de discussão clínica: o Núcleo de Pesquisa em Psicose (desde 1999) - um projeto do IPSM-MG em parceria com o IRS; e a Sessão Clínica do IRS (2000 a 2005). Ambos os espaços de orientação psicanalítica, sendo as entrevistas realizadas por analistas da EBP-MG.
} 
O interessante dessa perspectiva, como nos diz Antônio Beneti, é que “a prática da apresentação de enfermos realizada pelo psicanalista no âmbito das instituições de saúde mental possibilita uma mudança radical na clínica desenvolvida nas mesmas” (BENETI, 1994, p.94), pois seu caráter de transmissão possibilita uma reorientação da clínica — seja no lugar dado à palavra, ao saber do paciente, seja no manejo que exemplifica.

Se introduzir a dimensão do particular do sujeito no universal da instituição é a contribuição que a psicanálise pode trazer, a forma como isso pode ser feito é abrir espaço na instituição para o sujeito da palavra, é introduzir o particular do sujeito no universal da instituição. Como nos diz Viganò: "Colocar no centro do trabalho institucional o ato da palavra, mais precisamente o ato que cria a palavra (...)" (1998, p.246).

Mas, ainda mais interessante do que esse efeito sobre a equipe e sobre a instituição é o efeito sobre o sujeito. A intenção é que, neste único encontro, o apresentador consiga algum tipo de efeito sobre o paciente, seja sua implicação subjetiva, seja um reforço dos laços transferenciais, seja um reposicionamento diante de sua própria fala....

E quase sempre os efeitos são muito positivos para o paciente. Numa pesquisa que investiga os efeitos da apresentação de pacientes no tratamento psicanalítico do sujeito psicótico, ${ }^{7}$ alguns funcionários do Instituto Raul Soares foram interrogados quanto às modificações que percebiam nos pacientes após a entrevista.

Os profissionais de nível superior indicaram que de hábito, após a entrevista, era possível perceber alguma modificação do paciente em relação ao tratamento ou à equipe, como, por exemplo, sua implicação no tratamento, uma posição de maior confiança na equipe, às vezes uma organização do delírio, ou uma retomada pelo próprio paciente de pontos de sua história que apareceram na entrevista. Às vezes, esse efeito era um apaziguamento. E mesmo quando não se percebia um efeito direto, as mudanças produzidas na equipe repercutiam sobre paciente. Como disse um dos entrevistados: "Se a equipe muda de posição com o paciente, logicamente ele sente isso. Ele percebe esta mudança. Logica-

\footnotetext{
${ }^{7}$ Tomamos como referência, aqui, dados levantados pela pesquisa: "Sobre a eficácia clínica da apresentação de pacientes: investigações sobre o emprego da apresentação de pacientes no tratamento psicanalítico do sujeito psicótico”. Trata-se de uma pesquisa que investiga os efeitos clínicos e institucionais produzidos pela Sessão Clínica do IRS — espaço aberto à comunidade clínica do hospital, para trabalhar "casos difíceis”, sob a perspectiva psicanalítica da construção do caso, realizada, geralmente, a partir da entrevista com o paciente. Esta sessão clínica foi realizada no período de 1999 a 2004, no IRS — Fhemig, sob a orientação do psicanalista e, na época diretor do hospital, dr. Wellerson Durães de Alkmim. Mais tarde, seus efeitos passaram a ser trabalhados a partir de uma parceria com a UFMG, num projeto de pesquisa coordenado pelo dr. Jésus Santiago, financiado pelo CNPq, da qual faço parte na qualidade de pesquisador.
} 
mente, ele melhora. Ele está vendo um investimento, uma nova forma de lidar" (FERREIRA, 2006).

Na literatura atual, há relatos de casos surpreendentes, ${ }^{8}$ nos quais a apresentação parece ter tido para o paciente o peso de um acontecimento, de um encontro que toca em sua posição subjetiva, levando a verdadeiras retificações subjetivas. Tomemos como exemplo um pequeno fragmento apresentado por Liliane Cazenave:

"Recordo por exemplo um adolescente, que se caracterizava por ser muito agitado, jogava a bola o tempo todo na sessão e a partir da apresentação que participou sem jogar, sentado e conversando, passou a situar que ele já estava no momento de deixar de jogar para passar a falar. Foi a conclusão que ele extraiu da entrevista mesma para seu tratamento: uma mudança de posição com relação à palavra. Este é um saldo que o sujeito testemunhou." (CAZENAVE, 2002, p.80) ${ }^{9}$

Podemos dizer que os efeitos clínicos que podem ser produzidos decorrem não apenas do enfoque do apresentador, interessado na subjetividade do paciente, mas também por alguns outros fatores que favorecem a transferência.

Um primeiro ponto que parece contribuir para que uma apresentação tenha efeitos sobre o tratamento é o fato de que, em geral, é a equipe que solicita a apresentação por encontrar-se com algum tipo de questão em relação a algum caso muito difícil, com dúvida diagnóstica, no manejo da transferência, ou na direção do tratamento, no encaminhamento. Há, portanto, uma demanda da equipe ao analista, mais precisamente, uma transferência àquele que fará a entrevista, ou à psicanálise.

O efeito da transferência dos técnicos, no meio no qual circula o paciente, produz efeitos no paciente - o lugar na transferência, que o paciente reserva ao apresentador durante a condução da entrevista é, de início, importado da relação deste com a equipe e, conseqüentemente, da posição desta com o apresentador.

Outro ponto que pode favorecer o efeito clínico é o fato de o paciente consentir na apresentação - condição fundamental para a realização da entrevista. Em geral, esse consentimento advém da percepção que o paciente tem de que o terapeuta e/ou a equipe tem esperança de que isso vai apontar-lhe algo no que concerne ao seu tratamento.

\footnotetext{
${ }^{8}$ Sobre o tema, cf. Ferreira (2006), Sobre o efeito clínico da Apresentação de Pacientes, in Papéis de Psicanálise: pequenas invenções psicóticas, ano 3, n.2 (maio 2006) Belo Horizonte: Instituto de Psicanálise e Saúde Mental de Minas Gerais. E Ferreira (2006a) Apresentação de pacientes: (re) descobrindo a dimensão clínica. Dissertação de mestrado. UFMG.

${ }^{9}$ Tradução livre do espanhol.
} 
Muitos pacientes chegam mesmo a ter interesse em ser apresentados, sabendo que encontrarão um auditório atento a seus problemas, em ocasião um tanto ou quanto solene, bem diferente da entrevista cotidiana, individual - um terreno fértil para compartilhar seja seu drama, seja suas inquietudes (CLASTRES et al.,1991, p.40).

E realmente, a apresentação costuma ser benéfica, pois pela particularidade da situação, a entrevista de paciente parece favorecer certa formalização do discurso. Isto porque, como nos indica Geneviève Morel (1999): diferentemente do que se dá, por exemplo, nas entrevistas preliminares, quando o analista pode utilizar-se de vários encontros para esclarecer os pontos de interesse, na apresentação, sua limitação a uma única entrevista pede ao apresentador uma posição mais ativa. Da mesma forma, o paciente sabe que não irá retornar àquela situação, o que resulta num efeito de condensação, de precipitação do tempo de compreender e do que é preciso dizer, pois se sabe que esse encontro será único.

Resgatamos a dimensão clínica da apresentação, mas ao que parece, ainda não sabemos, verdadeiramente, o alcance de suas possibilidades. Sem dúvida, há um campo fértil de investigação, e, por certo, muitas questões para responder: Em que se sustentam os efeitos que aí se produzem? Do lado do analista, o que o autoriza ao ato em uma apresentação? E do lado do paciente, o que o torna suscetível a essa intervenção? Qual é a função do público?

Mais do que respostas, o que se tem são suposições, elaborações iniciais, mas que já possibilitam estabelecer algumas coordenadas para uma investigação mais sistemática, que ainda, e cada vez mais, se faz necessária.

Por fim, é importante marcar que não são todas as apresentações que produzem esse tipo de efeito; pelo contrário, podemos mesmo dizer que esse é um encontro raro. É preciso considerar que não há garantia de que os resultados sejam sempre positivos: pode ser que nada se produza num encontro, mas pode ser, também, que testemunhemos efeitos desencadeantes ou de reagudização de uma crise, por exemplo. Assim, formalizar os fundamentos clínicos que aí operam, sistematizar sua aplicação, decerto contribuiria muito, não apenas para ampliar as possibilidades de se produzir um bom encontro e para diminuição dos riscos, mas também para aplicar suas conseqüências no tratamento psicanalítico da psicose, de forma geral.

Nas palavras de Colette Soler: "resumindo, diria que os benefícios são instruir, colocar à prova nossa técnica de entrevista e experimentar os limites e as condições de entrada do discurso analítico” (SOLER, 1988, p.17). ${ }^{10}$

10 Tradução livre do espanhol. 


\section{REFERÊNCIAS}

BARRETO, F. P. (1988) História da psiquiatria. Curso de Residência Instituto Raul Soares da Fundação Hospitalar do Estado de Minas Gerais (IRS/Fhemig). (Mimeo)

BENETI, A. (1994) Sobre a apresentação de enfermos. Opção lacaniana. Revista Brasileira Internacional de Psicanálise, v. 1, São Paulo: Edições Eólia, p.93-96.

CAZENAVE, L. (2002) Los niños en la presentación de enfermos. Registros. Niños y psicoanálisis. Tomo rosa y celeste, año 7, p.77-82.

CLASTRES, G. et al. (1993) "La presentación de enfermos: buen uso y falsos problemas. Mesa Redonda”, in BROCA, R. et al. (org.). Psicosis y psicoanalisis. Buenos Aires: Manantial.

FERREIRA, C. (2006) "Apresentação de pacientes: (re)descobrindo a dimensão clínica”. Dissertação de mestrado, UFMG.

FOUCAULT, M. (1973-1974/2005) El poder psiquátrico. Curso em El Collège de France. Buenos Aires: Fondo de Cultura Económica.

LACAN, J. (1976) El Seminário, Libro 23. El Síntoma. CD-Rom — Obra de Jacques Lacan, Folio Views. Clase 7, Palabras impuestas, del 17 de febrero de 1976.

LANTÉRI-LAURA, G. (1989) Prefácio, in BERCHERIE, P. Os fundamentos da clínica: história e estrutura do saber. Rio de Janeiro: Jorge Zahar.

LAURENT, E. (1989) A apresentação de pacientes. Clínica Lacaniana, Publicação de Psicanálise da Biblioteca Freudiana, v.3. São Paulo: Unicopi, p.149-187.

LÉGER, C. (1998) “Elogio a apresentação de pacientes. Um dispositivo adequado”, in MILLER, J.A. (Org.) Le conciliabule d'Angers. Effets de surprise dans lês psychoses. Le Paon, Collection par Jacques-Alain Miller. Paris: Agalma Éditeur.

LEGUIL, F. (1998) “Sobre as apresentações clínicas de Jacques Lacan”, in Lacan, você conhece? São Paulo: Cultura Editores.

MILLER, J.A. (1998) (Org.) Le conciliabule d'Angers. Effets de surprise dans lês psychoses. Le Paon, Paris: Agalma Éditeur.

(1996) Lições sobre a apresentação de doentes, in Matemas I. Rio de Janeiro: Jorge Zahar, p.38-149.

MOREL, G. (1999) A função do sintoma. Revista de Psicanálise, ano VI, n.11. Bahia: Publicação da Escola Brasileira de Psicanálise, p.4-27.

PESSOTTI, Isaias. (1996) O século dos manicômios. São Paulo: Ed.34.

QUINET, A. (1997) “Apresentação de pacientes”, in Teoria e clínica da psicose. Rio de Janeiro: Forense Universitária.

SOLER, C. (1988) La presentación de enfermos. Malentendido, v.3. Buenos Aires: Malentendido, p.57-61.

SWAIN, G. (2000) "La apropriación neurológica de la histeria", in: GAUCHET, M. \& SWAIN, G. El verdadero Charcot. Los caminos imprevistos del inconsciente. Buenos Aires: Ediciones Nueva Visión.

VIGANÒ, C. (1998) Da instituição ao Discurso, in: Primeiro congresso da Associação Mundial de Psicanálise. Barcelona. Relatório das Escolas - EBP.Sl. Cultura.

Cristiana Miranda Ramos Ferreira

cristianaramos@terra.com.br 